\title{
Mild head injury with isolated third nerve palsy
}

\author{
P Muthu, P Pritty
}

\begin{abstract}
Traumatic isolated cranial nerve palsies are uncommon and when they do occur, they are usually associated with severe head trauma. Cranial nerve palsy associated with mild head injury is rare. A case is reported of complete left third nerve palsy associated with mild head injury. The rate of recovery for complete third nerve palsy is slow and prolonged. The ptosis recovered in 10 months; the divergent squint required botulinum toxin to the lateral rectus muscle followed by surgery.

(Emerg Med f 2001;18:310-311)
\end{abstract}

Keywords: head injury; oculomotor nerve palsy

Case report

A 52 year old woman was brought to the accident and emergency (A\&E) department with history of a fall. While walking in town, her husband pushed her aside to avoid being hit by a van and took most of the impact himself. The patient hit the pavement and sustained injury to the left side of her head. She did not lose consciousness but had no memory of events surrounding the accident. On examination, she was confused and GCS was 14/15. Her vital signs were normal. Left sided ptosis with dilated pupil was noted. There was an abrasion on the left side of her forehead and her left chin (fig 1). Her cardiovascular system, respiratory system and nervous system were clinically nor-

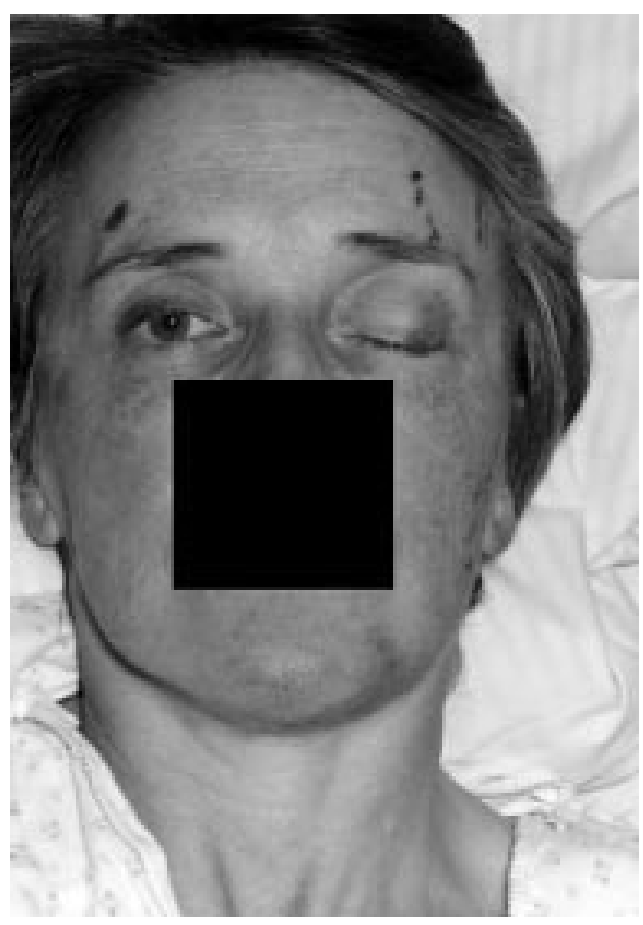

Figure 1 Photograph of the patient showing an abrasion on the left side of her forehead and her left chin. mal. There was tenderness of her left lower jaw, left shoulder and right heel.

Radiographs of the skull, cervical spine, chest and left shoulder were normal. A radiograph of the foot revealed hairline fracture of the right calcaneum. Computed tomography of the head was reported as normal. The patient was referred to the ophthalmology team, who suggested computed tomography of the orbit, which showed no abnormality. Magnetic resonance imaging of the brain with angiosequence showed no abnormality. The patient was reviewed by a neurologist, who suggested an extrinsic ophthalmoplegia. The patient was then reviewed in the ophthalmology and head injury rehabilitation outpatients departments.

The third nerve palsy only partially recovered, so botulinum toxin was injected into the lateral rectus muscle to prevent contracture. Ptosis recovered after 10 months, but the patient continued to have troublesome diplopia. She underwent strabismus surgery to the recti muscles (transposition of medial and lateral recti muscles) to restore the eye to the primary position. She was found to have bilateral optic atrophy and visual field defects. She is still being followed up in ophthalmology clinics.

\section{Discussion}

Isolated third nerve palsy attributable to trauma is not common. Tiffin et al performed a retrospective study of acquired 3rd, 4 th and 6th cranial nerve palsies of varying aetiologies that were seen in the orthoptic department at Ninewells Hospital, Dundee, UK over a nine year period. They found no cases of isolated 3rd nerve palsy attributable to trauma. Solomons et al ${ }^{2}$ reported $1.2 \%$ incidence of isolated direct third nerve palsy in 2100 patients with head injury treated in the neurosurgery department of a teaching hospital, Cape Town, South Africa over a 12 year period. They showed that direct injury to third nerve is uncommon compared with the indirect injury attributable to expanding haematoma. Similarly, Memon and Paine $^{3}$ reported $1.1 \%$ incidence of direct third nerve palsy in 1100 head injuries, studied at the University Hospital, Saskatoon, Canada over a 10 year period. There were no cases of isolated 3rd nerve palsy attributable to mild head injury in both the studies by Solomons et $a l$ and Memon et al. Kruger et $a l^{4}$ reported bilateral oculomotor nerve palsies in two moderate to severe head injury patients. Elston ${ }^{5}$ studied 20 patients referred to Moorfields Eye Hospital, UK by ophthalmologists and neurosurgeons over a four year period because of ocular motility problems after traumatic third nerve palsy. All the patients sustained a closed head injury with prolonged loss of consciousness in a high speed deceleration accident. 
Rucker, ${ }^{6}$ in his study of 1000 patients of 3rd, 4 th and 6 th cranial nerves, reported $15 \%$ incidence of 3rd nerve palsy attributable to head trauma. Richards et al reported a much larger retrospective series of 4176 cases of acquired $3 \mathrm{rd}, 4$ th and 6 th cranial nerve palsies seen over 40 years in the Mayo Clinic Department of Ophthalmology. They found a 15\% occurrence of isolated 3rd nerve palsy attributable to head trauma; unfortunately, the severity of head trauma was not specified in the studies by Rucker and Richards et al. It has been reported that trauma is the commonest cause of 4 th nerve palsy. ${ }^{78}$ Also, 4 th nerve palsy can occur after apparently trivial head trauma ${ }^{8}$ probably because of its long intracranial course and a very slender connection to the brain stem. ${ }^{9}$

It seems that traumatic oculomotor nerve palsies occur because of differential movements between the brain stem and supratentorial structures, which can cause rootlet avulsion and distal fascicular damage. ${ }^{10}$ The distance the oculomotor nerve travels after its exit from brainstem is the shortest route among the nerves departing through the superior orbital fissure. During its course, it runs over the tough posterior petroclinoid ligament where it may be especially susceptible to damage, as it is stretched when the brain stem shifts downwards at the moment of impact to the head. ${ }^{11}$ When isolated third nerve palsies occur, the closed head injury sufficient to cause such palsies almost always entails a loss of consciousness or fractured skull. Minor head trauma may, however precipitate oculomotor nerve palsy in patients with occult intracranial mass lesion because of the mechanical stress. $^{9}{ }^{12} 13$ Our patient, however did not have any of the above mentioned features, which is a distinct rarity. Magnetic resonance angiography plays an important diagnostic part in the evaluation of patients with isolated 3rd cranial nerve palsy. In our patient however, MRI brain with angiosequence neither shows any abnormalities consistent with shearing injury in the dorsal midbrain or haemorrhage at the exit site of oculomotor nerve ${ }^{14}$ nor any evidence of a posterior communicating artery aneurysm.

It is well known that the patients with oculomotor nerve palsy are extremely difficult to treat because of the involvement of multiple extraocular muscles. In our patient, the ptosis improved almost completely but had residual diplopia despite the use of botulinum toxin to prevent lateral rectus contracture followed by surgery to the recti muscles. Botulinum toxin extracted from Clostridium botulinum organisms is used to produce temporary muscle weakness in the treatment of strabismus, blepharospasm, and torticollis. The patient is currently using an occluding cosmetic contact lens in the left eye. This is consistent with Miller ${ }^{15}$ who suggested that there is no satisfactory surgical treatment for patients with complete 3rd nerve palsy.

It can be concluded from published literature that besides mechanical injuries such as rootlet avulsion from brain stem, the cranial nerves may suffer from disturbances in blood supply or the detrimental biochemical effects arising from head injury. This case illustrates that people who sustain mild head injury may suffer similar disturbances.

Contributors

PM initiated and wrote the paper and performed the literature search. PP discussed the idea and edited the paper. $\mathrm{PM}$ is the guarantor of this paper.

Funding: none.

Conflicts of interest: none.

1 Tiffin PAC, MacEwen CJ, Craig EA, et al. Acquired palsy of the oculomotor, trochlear and abducens nerves. Eye 1996;10:377-84.

2 Solomons NB, Solomon DJ, DeVilliers JC. Direct traumatic third nerve palsy. S Afr Med f 1980;58:109-11.

3 Memon MY, Paine KWE. Direct injury of the oculomotor nerve in craniocerebral trauma. $\mathcal{F}$ Neurosurg 1971;35:4614.

4 Kruger M, Noel P, Ectors P. Bilateral primary traumatic oculomotor nerve palsy. F Trauma 1986;26:1151-3.

5 Elston JS. Traumatic third nerve palsy. Br f Ophthalmol 1984;68:538-43.

6 Rucker CW. Paralysis of the third, fourth and sixth cranial nerves. Am f Ophthalmol 1958;46:787-94.

7 Richards BW, Jones FR, Young BR. Causes and prognosis in 4278 cases of paralysis of the oculomotor, trochlear and 4278 cases of paralysis of the oculomotor, trochlear and
abducens cranial nerves. Am 7 Ophthalmol 1992;113:48996

8 Kwartz J, Leatherbarrow B, Davis H. Diplopia following head injury. Injury 1990;21:351-2.

9 Kanski J. Clinical ophthalmology - a systematic approach. 4th ed. London: Butterworth Heinemann, 1999:622

0 Heinz J. Cranial nerve avulsion and other neural injuries. Med f Aust 1969;2: 1246-9.

11 Mariak Z, Mariak Z, Stankiewicz A. Cranial nerve II-VII njuries in fatal head trauma. Eur $\mathcal{F}$ Ophthalmol 1997;7:6872.

12 Eyster EF, Hoyt WF, Wilson CB. Oculomotor palsy from minor head trauma. $\mathcal{f} A M A$ 1972;220:1083-6.

13 Walter KA, Newman NJ, Lessell S. Oculomotor palsy from minor head trauma: initial sign of intracranial aneurysm. Neurology 1994;44:148-50.

14 Bacler LJ, Galetta SL, Bagley LJ, et al. Localization of traumatic oculomotor nerve palsy to the midbrain exit site by MRI. Am f Ophthalmol 1996;22:437-9.

15 Miller NR. The oculomotor nerves. Curr Opin Neurol 1996; 9:21-5 